$\begin{array}{cl}\begin{array}{c}\text { Revue } \\ \text { de I'histoire } \\ \text { des religions }\end{array} & \text { Revue de l'histoire des religions } \\ & \text { Genève, refuge et migrations (XV|e-XVIIe siècles) }\end{array}$

\title{
Gérard CoLAS, Penser l'icône en Inde ancienne
}

Turnhout, Brepols (« Bibliothèque de l'École des Hautes Études. Sciences religieuses », 158), 2012

\section{Gérard Toffin}

\section{OpenEdition}

Journals

Édition électronique

URL : http://journals.openedition.org/rhr/8359

DOI : $10.4000 /$ rhr.8359

ISSN : 2105-2573

Éditeur

Armand Colin

Édition imprimée

Date de publication : 1 mars 2015

Pagination : 95-97

ISBN : 9782200929657

ISSN : 0035-1423

Référence électronique

Gérard Toffin, "Gérard Colas, Penser l'icône en Inde ancienne », Revue de l'histoire des religions [En ligne], 1 | 2015, mis en ligne le, consulté le 22 septembre 2020. URL : http://journals.openedition.org/rhr/ 8359 ; DOI : https://doi.org/10.4000/rhr.8359

Ce document a été généré automatiquement le 22 septembre 2020.

Tous droits réservés 


\section{Gérard Colas, Penser l'icône en Inde ancienne}

Turnhout, Brepols (« Bibliothèque de l'École des Hautes Études. Sciences religieuses », 158), 2012

\section{Gérard Toffin}

\section{RÉFÉRENCE}

Gérard CoLAs, Penser l'icône en Inde ancienne. Turnhout, Brepols (« Bibliothèque de l'École des Hautes Études. Sciences religieuses », 158), 2012, 24 cm, 213 p., $49 €$, ISBN

978-2-503-54378-7.

1 L'hindouisme est couramment associé à un panthéon luxuriant, à des divinités polymorphes, masculines et féminines, dont les multiples corps, figés dans des poses les plus diverses, se voient surchargés d'attributs et d'accessoires. L'iconographie des dieux déroute par sa complexité et fait l'objet d'un savoir spécialisé dont parlent les traités de beaux-arts et d'architecture. Le bestiaire représenté lui aussi est immense ; sa diversité rappelle le polythéisme ancien de la Méditerranée grecque et romaine. Gérard Colas, qui étudie l'hindouisme principalement à partir de sources sanskrites et dont on connaît les travaux savants en la matière, s'attache dans son dernier livre à ces images divines (pratimā, mūrti, sva-rūpa en sanskrit). Il retient le mot "icône» pour les désigner, un mot issu du christianisme orthodoxe. L'auteur a choisi de limiter son sujet à l'Inde ancienne, c'est-à-dire à la période qui va de la société harappéenne jusqu'au XII siècle de notre ère, juste avant l'islamisation du sous-continent. L'ouvrage ne s'intéresse pas à l'iconographie proprement dite, mais aux conceptions philosophiques sous-tendant la représentation concrète, matérielle des dieux. Nous sommes ici dans une histoire culturelle des mentalités, non dans une histoire de l'art.

Des dieux propres à la culture harappéenne, nous ne savons presque rien ; l'écriture en usage durant cette période reste encore indéchiffrable et seuls quelques témoignages archéologiques nous sont parvenus. L'étude proprement dite commence donc avec le 
védisme, dont les plus anciens textes remontent à une période située entre 1200 et 800 avant notre ère. Pour Gérard Colas, le védisme ancien n'est ni iconique ni aniconique (p. 24). Il témoigne d'une poétique du langage et il met l'accent sur des évocations mises en œuvre dans et par la parole. Progressivement cependant, les dieux, rarement perceptibles pour l'homme, apparaissent de moins en moins. Seule la pratique rituelle active leur visibilité, une visibilité toute mentale qui ne préfigure en rien la passion iconophile indienne postérieure. D'une manière générale, malgré quelques conceptions iconiques éparses, la figuration concrète des dieux dans des matériaux tels que la pierre et le bois n'est pas encore à l'ordre du jour.

3 La période suivante commence à partir du $\mathrm{II}^{\mathrm{e}}$ siècle avant notre ère. Elle marque un tournant dans la mesure où les élites politiques exploitent l'icône, tout en maintenant une certaine distance vis-à-vis d'elle. Les Maurya auraient utilisé sciemment les images divines pour asseoir leur pouvoir, augmenter leur trésor royal, démoraliser l'ennemi en profitant de la crédulité populaire. Tous les moyens sont bons pour le roi, même ceux qui touchent à la religion. Selon l'Arthashāstra, ils interviennent directement dans l'organisation des cultes des icônes au moyen de leur administration et de leurs agents. Les monarques eux-mêmes se font représenter en statues plus ou moins divinisées.

4 Les conceptions philosophiques et religieuses, quant à elles, sont d'une très grande complexité et expriment des idées divergentes selon les âges et même à l'intérieur d'une même époque. Certains textes identifient l'icône au corps du dieu et en font un être sensible. L'image divine devient alors animée: c'est une incarnation anthropomorphe. Le dévot y voit une manifestation complète et immédiate de la divinité. D'autres écrits (la mīmāmsā par exemple) marquent au contraire une distance par rapport à cette identification et placent l'icône à une place inférieure des apparences divines. Le philosophe Shabara (seconde partie $\mathrm{du} \mathrm{IV}^{\mathrm{e}}$ ou du $\mathrm{V}^{\mathrm{e}}$ siècle) par exemple attaque l'idée selon laquelle les dieux posséderaient un corps. Les puissances divines ne pourraient pas avoir de propriété ni se prévaloir de l'usage d'un village ou d'un territoire. Ces idées divergentes ne s'opposent pas, nous dit l'auteur, elles se côtoient et éventuellement s'ajoutent, mais ne se considèrent pas comme opposées.

5 Le statut de l'image au sein du bouddhisme est longuement traité. Le troisième chapitre lui est tout entier consacré. Cette religion marque d'abord une grande réticence à l'endroit de l'icône. Le Buddha brille au départ par son absence ; il est représenté par ses empreintes de pieds, des trônes inoccupés, des reliques, l'arbre de l'illumination, etc., non par son corps. Les choses changent dès le $\mathrm{I}^{\text {er }}$ siècle avant notre ère. Progressivement, le Buddha devient un sujet d'iconographie religieuse à l'égal des dieux hindous. Contrairement à l'hindouisme, le bouddhisme se caractérise surtout par l'importance accordée au culte des reliques (souvent abritées dans des stūpas, mais pas toujours), qui devint ainsi comme un substitut de l'image. Pour Gérard Colas, cette vénération a servi de rempart provisoire contre le culte de l'icône (cendres humaines contre figuration divine). C'est l'un des passages les plus novateurs du livre.

6 Il s'agit au total d'un ouvrage savant, par endroits fort technique, mais toujours clair, qui offre au lecteur indianiste une synthèse utile de la conception de l'image dans l'Inde ancienne. Dans chaque culture, représenter le sacré fait l'objet de réponses complexes qui peuvent s'avérer contradictoires L'Inde ne fait pas exception à la règle, contrairement aux images superficielles que l'on peut parfois en avoir. On regrettera évidemment que l'auteur s'arrête au XII siècle, à l'aube de la grande division entre conceptions hindoues saguna (qui voient la divinité sous ses formes "qualifiées", 
iconiques) et nirguna (pour lesquelles le dieu ne doit pas être représenté, le culte s'adressant à une puissance divine sans forme), si influentes et tenaces de nos jours. Il l'évoque en conclusion, mentionnant les influences de l'islam à partir du XII siècle. L'ouvrage a toutefois le grand mérite de montrer que cette division entre iconophiles et iconophobes s'enracine dans des clivages très anciens.

\section{AUTEURS}

\section{GÉRARD TOFFIN}

Centre national de la recherche scientifique. 